\title{
O enfrentamento ao fenômeno discriminatório em uma população de adultos
}

\section{I ${ }^{1}$ Tatiana Stümer Badalotti, ${ }^{2}$ Ramona Fernanda Ceriotti Toassi, ${ }^{3}$ Roger Keller Celeste I}

Resumo: A discriminação é um fenômeno social causador de prejuízos e iniquidades em saúde. O objetivo desta pesquisa foi explorar a discriminação e suas formas de enfrentamento por servidores universitários. Trata-se de estudo qualitativo analítico, usando entrevistas individuais semiestruturadas, interpretadas pela fenomenologia. A amostra foi intencional, definida pela técnica da bola de neve. Utilizou-se a análise de conteúdo temática proposta por Bardin, com o auxílio do software NVivo para definir categorias analíticas. Os principais resultados revelam um modelo de enfrentamento/combate à discriminação, no qual as categorias se inter-relacionam. A categoria cultura ocupa papel central, interligando as estratégias de cotas, educação formal, legislação e políticas públicas, mídias e educação informal. As cotas viabilizam acesso à educação formal, que reduz discriminação e aumenta oportunidades entre os indivíduos. As leis e políticas alteram o comportamento, tanto pelo seu papel educativo, quanto coercitivo. A mídia permite a interação e discussão sobre nós críticos da discriminação na sociedade. A educação informal cria ambientes viáveis de discussão e estimula o convívio menos discriminatório desde a infância. Este estudo traz novas perspectivas e abordagens alternativas para compreender formas de enfrentamento à discriminação, que é um fenômeno injusto, que cruza múltiplos espaços e contextos sociais.

> Palavras-chave: discriminação social; preconceito; estratégias; pesquisa qualitativa; fenomenologia.

\author{
1 Faculdade de Odontologia, \\ Pontifícia Universidade Católica \\ do Rio Grande do Sul. Porto \\ Alegre-RS, Brasil (tatibadalotti@ \\ hotmail.com). \\ ORCID: 0000-0002-2845-8983. \\ 2 Faculdade de Odontologia, \\ Universidade Federal do Rio \\ Grande do Sul. Porto Alegre-RS, \\ Brasil (ramona.fernanda@ufrgs.br). \\ ORCID: 0000-0003-4653-5732.

\footnotetext{
${ }^{3}$ Faculdade de Odontologia, Universidade Federal do Rio Grande do Sul. Porto Alegre-RS, Brasil (roger.keller@ufrgs.br).
} \\ ORCID: 0000-0002-2468-6655.
}

Recebido em: 14/02/2019 Revisado em: 09/05/2019 Aprovado em: 06/06/2019 


\section{Introdução}

A discriminação é um processo pelo qual o membro de um grupo socialmente definido é tratado de forma diferente, especialmente injusta, por pertencer a esse grupo, gerando desvantagens e prejuízos. São comportamentos observáveis, atitudes caracterizadas pelo tratamento diferente e desigual de pessoas ou de grupos em razão das suas origens, pertencimentos, aparências ou opinióes, reais ou supostas, e que podem ocorrer em qualquer contexto da vida, seja na escola, em casa, no trabalho, na rua e durante qualquer fase da vida (KRIEGER, 2001; DOVIDIO, 2010; BASTOS; FAERSTEIN, 2012). Manifesta-se no campo das açôes como uma expressão do preconceito, que é uma ideia social e historicamente construída sobre algum indivíduo, e é feita de acordo com a aparência e o comportamento do mesmo (BASTOS et al., 2010). Além do preconceito, o estigma correlaciona-se com a discriminação na medida em que os atributos do indivíduo levam ao tratamento injusto ou diferenciado em relação aos indivíduos que possuem atributos diferentes. $\mathrm{O}$ estigma tem por eixo o sujeito, seu corpo e sua experiência, e se expressa como uma marca, uma diferença de valor negativo que está ligada a desigualdades sociais (GOFFMAN, 1988).

O estudo do fenômeno da discriminaçáo tem sido expressivo ao longo das décadas, com abordagens sobre gênero, sexualidade, idade, raça/etnia, de forma separada ou interligada. A maioria dos estudos aborda a discriminação interpessoal, onde um indivíduo age de forma diferente em relação ao outro (KRIEGER, 2014). No ano de 2015, o assunto permeou os debates da Assembleia Geral das Nações Unidas, já que o crescimento econômico resultou em iniquidades em saúde (UNESCO, 2016). De acordo com o relatório da Assembleia, as desigualdades sociais em saúde, acesso a serviços e a discriminação vão contra valores para o estabelecimento de uma sociedade pacífica e coesa.

O fenômeno discriminatório é entendido como fator causador de prejuízos e iniquidades em saúde. Estudos revelam a influência do estresse frente à discriminação, ao gerar sofrimento psicológico, adoção de comportamentos negativos, como o consumo de álcool e tabaco, alteração do sono, além das alteraçôes nos sistemas fisiológicos do organismo (BASÁÑEZ et al., 2013; COELHO; BASTOS; CELESTE, 2015; PARADIES, 2006; WILLIAMS; MOHAMMED, 2009). Os atos discriminatórios relacionados têm como consequência a desigualdade de acesso a cuidados em saúde, insegurança e impedimento de sair de casa (GOODMAN 
et al., 2017; WALLACE; NAZROO; BÉCARES, 2016). Isso resulta em sintomas relacionados à ansiedade e ao estresse crônicos, como depressão, elevação da pressão arterial, diabetes e doença renal (ASSARI et al., 2017; BIGLAN; VAN RYZIN; HAWKINS, 2017; CARTER et al., 2016; PARK et al., 2017; TAQUETTE, 2010).

No Brasil, ainda há poucos estudos analisando o significado das experiências discriminatórias por diferentes estratos populacionais e sujeitos, sob uma perspectiva abrangente e não restrita a algum tipo particular de discriminação. Também existe pouco conhecimento sobre efetivas estratégias de enfrentamento à discriminação em diferentes contextos. Estudos com esta proposta poderiam informar sobre as formas de sociabilidade predominantes no país, bem como fornecer subsídios aos trabalhos no campo da saúde que procuram vincular a discriminação com processos ligados à saúde-doença. Diante desse contexto, o objetivo da presente pesquisa é explorar o fenômeno da discriminação e formas de enfrentamento aos fenômenos discriminatórios por servidores da Universidade Federal do Rio Grande do Sul (UFRGS).

Para auxiliar a compreensão da discriminação como um fenômeno que varia de acordo com o contexto ou situaçáo de vida do indivíduo, fez-se o uso da fenomenologia. Trata-se de um método filosófico que surgiu no início do século XX, na Alemanha, sob a ótica de Edmundo Husserl, que influenciou outros filósofos como Martin Heidegger e Merleau-Ponty. Martin Heidegger entendia que "o ser" só pode ser compreendido como sua estrutura de ser no mundo, não existindo separado do mundo em que se vive. A fenomenologia é uma "maneira ou estilo de pensar" em que o próprio indivíduo fornece significado aos conceitos, enquanto ser humano envolvido no mundo em que vive (MENESES; GOMES, 2008). A percepção da discriminação representa um envolvimento subjetivo com o ambiente em que se vive, o que pode confundir o indivíduo sobre a quantidade de eventos de que é alvo. Os indivíduos que são alvos crônicos dos atos discriminatórios, que pertencem a grupos socialmente estigmatizados, mantêm-se em estado de alerta para qualquer sinal sutil de discriminação. Isso pode ocasionar um viés de vigilância no momento em que um ato ambíguo e não discriminatório é identificado como tal. As motivaçôes para essas atitudes podem ser explicadas como um mecanismo de autoproteção e melhora de autoestima. Por outro lado, existe o viés de minimização, onde os indivíduos negam, não percebem ou subestimam os atos sofridos (LEWIS; COGBURN; WILLIAMS, 2015; MAJOR; QUINTON; McCOY, 2006). 


\section{Métodos}

Trata-se de um estudo com abordagem qualitativa analítica, que buscou gerar informaçóes por meio da realização de entrevistas individuais semiestruturadas, as quais foram interpretadas pela perspectiva teórica da fenomenologia. O campo de investigaçáo foi a Universidade Federal do Rio Grande do Sul (UFRGS), em Porto Alegre, Rio Grande do Sul.

Os participantes da pesquisa foram 18 servidores técnico-administrativos, trabalhadores de diversos setores da Universidade, de ambos os sexos, de diferentes idades e graus de instrução. Dos 18 servidores, a maioria era mulher, branca, com ensino superior completo. A idade variou de 30 a 56 anos (tabela 1).

\section{Tabela 1. Caracterização dos entrevistados}

\begin{tabular}{lc}
\hline VARIÁVEIS & $\mathbf{n}$ \\
\hline Sexo & 13 \\
\hline Feminino & 5 \\
\hline Masculino & \\
\hline Faixa etária & 5 \\
\hline $30-35$ anos & 4 \\
\hline $36-40$ anos & 2 \\
\hline $41-45$ anos & 1 \\
\hline $46-50$ anos & 5 \\
\hline $51-55$ anos & 1 \\
\hline $56-60$ anos & 12 \\
\hline Cor da pele autodeclarada & 6 \\
\hline Branca & 2 \\
\hline Negra & 3 \\
\hline Escolaridade & 13 \\
\hline Ensino fundamental incompleto & 18 \\
\hline Ensino médio completo & \\
\hline Ensino superior completo & \\
\hline TOTAL & \\
\hline
\end{tabular}

Fonte: elaboração própria 
A opção de a amostra ser composta por servidores adultos é porque se acredita que a faixa etária e o nível educacional podem refletir em experiências e percepçôes diferentes sobre a discriminação. Além disso, não existem estudos prévios conhecidos sobre o tema que envolvam esse perfil populacional.

A amostragem foi intencional e o seu tamanho definido pela técnica da bola de neve, ou seja, realizou-se uma primeira entrevista em profundidade com um sujeito indicado por sua vivência pessoal. A partir da transcrição e análise do material coletado, retornou-se ao campo e selecionou-se um segundo sujeito, indicado pelo primeiro, para realizar a entrevista de maneira similar e com questóes mais bem construídas. Dessa forma, sucessivamente, partiu-se para as demais entrevistas, até que em um determinado momento não se encontraram novas informaçóes relevantes para o foco específico da pesquisa. Esse fato, aliado a uma avaliação da densidade do material textual produzido pelas entrevistas, determinou a conclusão do trabalho de campo (TURATO, 2011). O período de realização das entrevistas começou no mês de setembro de 2016, com término em maio de 2017.

As entrevistas foram realizadas por uma única pesquisadora, seguindo um roteiro pré-testado, de forma individual, gravadas por equipamento de áudio e transcritas na íntegra. As perguntas do roteiro eram abertas e serviam como norteadoras do diálogo para contemplar os objetivos do estudo. $\mathrm{O}$ roteiro incluía três tópicos principais: 1) as experiências de discriminação; 2) reaçôes à discriminação; e 3) estratégias utilizadas para enfrentamento e redução do preconceito e discriminação.

Houve a triangulaçáo de informaçóes, ou seja, todas as transcriçôes foram devolvidas aos entrevistados para que pudessem lê-las, verificando se estavam de acordo com as ideias apresentadas e, se julgassem necessário, complementassem seus depoimentos. O conteúdo das entrevistas foi inserido no software NVivo Pro 11.2 para auxiliar no processo de análise dos dados. O material textual produzido a partir da transcrição das entrevistas foi interpretado seguindo o método da análise de conteúdo temática (BARDIN, 2011). Esse tipo de análise busca os sentidos e o conteúdo das mensagens e é dividido em três principais etapas. A primeira é a pré-análise e envolve a leitura flutuante das entrevistas para organizar e sistematizar as ideias. A fase seguinte caracteriza-se pela exploração do material, onde se selecionam as unidades de análise, neste caso os temas. Tais temas vão depender do objetivo inicial do estudo, as teorias a priori e as teorias do próprio 
pesquisador. Por fim, a terceira fase é onde se realizam o tratamento dos resultados obtidos e a sua interpretação.

O estudo foi avaliado e aprovado pelo Comitê de Ética em Pesquisa da Universidade Federal do Rio Grande do Sul (protocolo número 303.041), obedecendo às exigências presentes nos documentos exigidos pela Resolução no 466 de 12 de dezembro de 2012. Os participantes assinaram o Termo de Consentimento Livre e Esclarecido.

\section{Resultados e Discussão}

A partir da análise do corpus, foi proposto um modelo de compreensão do fenômeno de enfrentamento da discriminação (figura 1). Nesse modelo, há seis categorias inter-relacionadas e a categoria "cultura" possui papel central, sendo detalhadas a seguir.

Conforme o modelo proposto, a cultura é determinante das estratégias de enfrentamento, sendo influenciada pela educação formal. Indiretamente as cotas influenciam na cultura, uma vez que alteram o status quo de acesso à educação formal, em especial a educação universitária. Por sua vez, a educação formal é apontada como uma forma de enfrentamento à discriminação por diminuir as desigualdades e aumentar as oportunidades entre os indivíduos. Já a legislação $e$ as políticas públicas viabilizam educar a população de forma mais coercitiva, por meio de algum tipo de penalização ou ônus financeiro. Os sujeitos acreditam que a coerção pela lei permite estabelecer limites e reduzir atitudes discriminatórias. As mídias são aparatos tecnológicos que permitem a interatividade social, além da troca de informaçóes e conhecimentos. Esses meios de comunicação são apontados como efetivos por trabalharem os nós críticos do fenômeno discriminatório. Por fim, a educação informal, por meio da discussão coletiva, diálogo, empoderamento e alteridade, pode criar um ambiente de convívio viável para trabalhar o tema da discriminação desde a infância. 
Figura 1. Modelo conceitual das categorias temáticas oriundas da análise

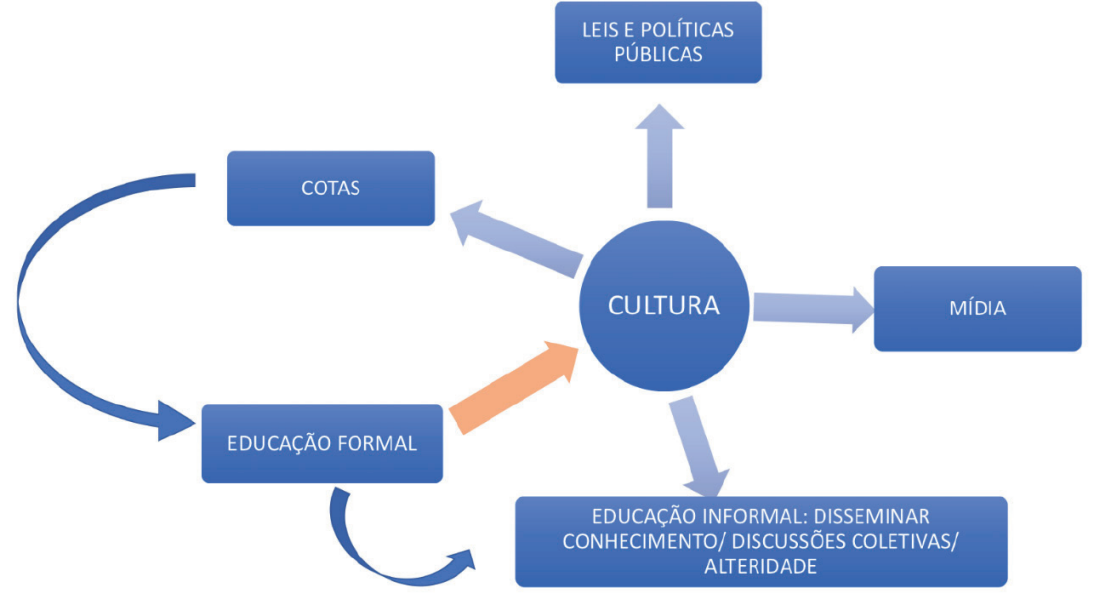

Fonte: elaboração própria

\section{Cultura}

A fenomenologia representa tudo o que se mostra ou se torna visível para a consciência em sua individualidade como postulado por Martin Heidegger (MENESES; GOMES, 2008). Ele entendia que o ser não existe em separado do seu contexto, e esse contexto representa a categoria cultura descrita aqui. As questóes culturais foram apontadas de forma ampla na fala dos entrevistados, que justificam o fenômeno discriminatório como algo relacionado com o meio em que o ser humano vive.

As questóes culturais têm que ser conversadas, têm que ser discutidas, têm que ser estranhadas num primeiro momento. E tu só estranha a partir de que tu tens o conhecimento de que outra coisa pode ser possível. (Entrevista 1, mulher, branca, 41 anos, ensino superior completo)

A compreensão da discriminação como um fenômeno cultural, cujo combate é complexo por sofrer influência de diversos fatores, também foi um dos pontos revelado nas entrevistas. Por vezes, o tom das falas era de descrença e desânimo ao pensar nas estratégias para coibir essas açóes.

Não sei te dizer como fazer, porque se a questão é cultural, é difícil de mudar porque tu terias que mexer nas estruturas, no pensamento, na forma desde o início. Porque naturalmente brasileiro discrimina o brasileiro, muitas culturas discriminam, mas brasileiro acho que em especial, o quanto ser rico, ser pobre, ser branco, ser preto faz diferença, o lugar que tu moras, o prédio que tu moras, ah tu moras no melhor prédio da rua ou tu moras na favela, tu moras no morro, tanta gente que mora no morro que é legal e tem 
tanta gente que mora num belo condomínio que não é tão legal assim. Não sei, acho que para mudar teria que mudar a estrutura, a cultura e a cultura eu náo vejo como mudar cultura. (Entrevista 17, mulher, branca, 56 anos, ensino médio completo).

\section{Educação formal}

A educação formal realizada pelas escolas e universidades, ou mesmo no trabalho, foi apontada como uma forma de transformar a cultura da sociedade em que se vive. Isso permite qualificar o indivíduo, reduzir a discriminação existente e esteve presente na fala de 11 entrevistados como principal estratégia de enfrentamento.

Educação! Pode até ser um clichê, mas a educação ela... a longo prazo como um movimento, como um processo paulatino, ela é uma grande soluçáo para muitas coisas. Então, digamos assim, para você ter uma educação que não só educa, mas que possibilite o acesso a ela. Uma educação que mostre para as pessoas que olha que um negro também é médico, negro também é escritor. (Entrevista 10, homem, negro, 31 anos, ensino superior completo)

Há o entendimento de que as açôes discriminatórias vivenciadas no cotidiano podem ser enfrentadas com a educação. $O$ investimento precoce na formação da criança pode conscientizar que ser diferente não implica tratar o outro de forma discriminatória ou injusta, e isso fica presente no relato que segue:

[...] eu sempre penso que muitas das questôes que a gente vive hoje, não só de discriminação, mas de outras questôes que perpassam, eu acho que muito vem da educação. Eu acho que se a gente investisse desde o início com as crianças, olhar o outro sem essas barreiras, ou essas questôes, contextualizar também porque que isso acontece, porque que não tem sentido de tu fazer determinado ato, de discriminar. (Entrevista 14, mulher, branca, 35 anos, ensino superior completo)

Estudo realizado em Belém observou a prática pedagógica transformadora, centrada no papel do professor em trabalhar as questóes das diferenças e as relaçóes sociais com as crianças. Tal prática permitiu manifestaçôes de atitudes positivas das crianças, com respeito e reconhecimento das diversidades raciais na escola (COSTA; SANTOS, 2014).

A escola pode ser compreendida como um espaço onde se trabalha o normal e o patológico segundo a ótica da psicologia e onde se discute a igualdade de direitos. É um ambiente onde é possível estimular o diálogo e reflexôes para mudanças (LOPES et al., 2008). Limitaçôes nesse processo de educar incluíram educadores que se diziam sobrecarregados de tarefas, sendo responsabilizados por soluçóes de problemas, além da falta de condiçôes em relação à qualificação, remuneração, dentre outras (NARDI; QUARTIERO, 2012). Nesse contexto, o enfrentamento da 
discriminação e do preconceito torna-se mais um desafio para esses trabalhadores. Por exemplo, a sexualidade é um tema que não é visto como prioritário e com o qual os educadores não se sentem aptos para trabalharem, além de torná-los vulneráveis sobre sua própria sexualidade e comportamento sexual (BORGES; MEYER, 2008).

A narrativa da entrevistada 1 demonstra a sua indignação com as políticas brasileiras que proíbem a abordagem de vários temas na escola, o que entende como um aspecto negativo no combate às desigualdades:

Acho que a escola agora nem pode mais falar sobre isso. Uma mordaça. Se a escola não é um espaço coletivo que tu possas usar como um espaço de discutir isso, onde vai ser? (Entrevista 1, mulher, branca, 41 anos, ensino superior completo)

A questão da educação sexual no ambiente escolar é prevista desde a década de 20 no Brasil. Entretanto, continua sendo debatida na sociedade, especialmente em segmentos religiosos de ensino que resistem à sua implementação.

\section{Cotas}

A política de cotas para ingresso no ensino superior, para obtenção de emprego ou ingresso em serviço público emergiu das entrevistas como meio de minimizar as desigualdades presentes no país. Compreende-se que não é um favor o acesso às mesmas oportunidades entre os indivíduos. As cotas são vistas como uma forma de compensação por todo o esforço e a história de vida dos afrodescententes ou grupos mais vulneráveis do território. Esse aspecto se tornou visível nas entrevistas.

Da mesma forma que as cotas, assim, não é um favor que as pessoas estão fazendo em te
dar um lugar praquele indígena, praquele índio, mas é um direito que a pessoa conseguiu,
enfim e entender isso como um direito. (Entrevista 1, mulher, branca, 41 anos, ensino
superior completo)
Aí teve a pressão também do pessoal, de alunos que acham que cotas não precisam existir,
porque tu vieste de um berço bom, teve oportunidade, tu nasceste, mas náo é todo mun-
do. Tem todos os que sofreram, os africanos que sofreram escravidão, e isso tudo é uma
compensaçáo, está certo, para mim está certo. (Entrevista 8, mulher, branca, 53 anos,
ensino fundamental incompleto)

Outro aspecto observado é a motivação na implementação da política de cotas brasileira. Existem percepçôes mostrando que as cotas têm uma relação social, abrangendo o histórico de vida dos indivíduos mais vulneráveis e com menor oportunidade de emprego e renda. Dessa forma, não devem ser contemplados estritamente os afrodescendentes. 
É uma vivência minha, pessoal, mas aí eu já tive um colega negro, filho de um dentista e de uma servidora, e ele tem direito às cotas raciais? Por que motivo? Se ele estudou numa excelente escola, fez uma excelente universidade, e ele entra por cotas? (Entrevista 17, mulher, branca, 56 anos, ensino médio completo)

As políticas de cotas são ações afirmativas que têm por objetivo neutralizar os efeitos discriminatórios por raça, gênero, idade ou outros fatores. Buscam corrigir as desigualdades por meio da valorização dos grupos atingidos (MOEHLECKE, 2002). De uma forma geral, a sua implementação deu-se por uma configuração cultural do país, e essa política inclusiva permite o acesso à educação formal, que por sua vez vai influenciar a cultura, segundo o corpus de análise.

O Brasil implementou a política de cotas para o acesso de negros e pardos à universidade pública pela lei 3708/01. Neste primeiro momento de implementação, até $40 \%$ das vagas eram ofertadas para esse recorte populacional. Em 2012, a lei 12.711 reserva $50 \%$ das vagas de ingresso na universidade e instituiçóes federais de ensino técnico para os estudantes oriundos de escolas públicas e pertencentes a famílias de baixa renda. Essa legislação garante o acesso de autodeclarados pretos, pardos, indígenas e portadores de deficiência. Atualmente, a reserva de vagas possui um componente racial e outro social.

Um estudo revela que diversos elementos, dentre eles a questão cultural, influenciam a implementação das ideias e políticas públicas (CAMPBELL, 2002). O Brasil e a África do Sul, por exemplo, apresentam diferentes motivaçôes na implementação da política de cotas. As cotas em universidades brasileiras se dão para promover a inclusão social e a diversidade. Já na África, as cotas permitem a formação do capital humano para suprir deficiências no mercado de trabalho, evitando desperdício de mão de obra e favorecendo a economia (SILVA, 2006).

Para além do acesso ao ensino superior, essa forma de promover a mobilidade de grupos desfavorecidos é garantida também no ingresso a cargos públicos mediante concurso. Existe a reserva de $20 \%$ das vagas para os negros, autodeclarados pretos e pardos no ato da inscrição.

Destacam-se, ainda, nas entrevistas, relatos sobre a discriminação percebida pelo fato de ser mulher e a importância de políticas inclusivas.

As organizaçôes teriam que promover isso, coisa que não fazem. Até políticas para conversar sobre isso. Porque tem as políticas afirmativas, até para mulher. Agora nas eleiçóes até os partidos são obrigados por lei para ter cotas para as mulheres. Teve partido que até foi 
multado porque não preencheu essa cota. Tem a questão das cotas raciais, cotas sociais, de acesso à universidade. (Entrevista 2, homem, negro, 32 anos, ensino superior completo).

No direito brasileiro, a questão da igualdade entre os gêneros é contemplada ao tratar da proteção do mercado de trabalho da mulher. A Lei no 9.100/1995 garante ao menos $20 \%$ dos cargos para as candidaturas das mulheres. Em 2003, foi criada a Secretaria Especial de Política para Mulheres, com o objetivo principal de "promover a igualdade entre homens e mulheres e combater todas as formas de preconceito e discriminação herdadas de uma sociedade patriarcal e excludente" (BRASIL, 2019).

A política de cotas, tanto para ingresso à universidade quanto a cargos públicos, permite a redução das desigualdades ao ofertar oportunidades para parcelas da população que não teriam tal acesso. Essa estratégia modifica o contexto cultural a longo prazo, na medida em que aumenta o número dos egressos cotistas de universidades e no mercado de trabalho. Acredita-se que a discriminação diminui ao alterar o estereótipo de determinados indivíduos:

Então, digamos assim, para você ter uma educação que não só educa, mas que possibilite o acesso a ela. Uma educação que mostre para as pessoas que olha que um negro também é médico, negro também é escritor. (Entrevista 10, homem, negro, 31 anos, ensino superior completo)

\section{Educação informal: discussóes coletivas e diálogo}

Classifica-se a educação informal como aqueles processos de aprendizagem que não resultam em titulação fornecida por órgãos ou instituiçôes reconhecidos para tal. Essa categoria diz respeito a conhecimentos obtidos e estimulados em ambiente familiar, conversas entre amigos ou colegas de trabalho, na forma de diálogo ou discussôes coletivas.

Os relatos deste estudo evidenciaram que esse tipo de abordagem é uma forma importante de enfrentamento da discriminação, uma vez que favorece o entendimento do fenômeno em espaços muito diversos na sociedade. Tais discussôes permitem entender a cultura sob diferentes pontos de vista, propiciando uma transformação de parâmetros, como expresso na seguinte fala:

Mas as questóes culturais têm que ser conversadas, têm que ser discutidas, têm que ser estranhadas num primeiro momento. E tu só estranhas a partir de que tu tens o conhecimento de que outra coisa pode ser possível... Então, quanto mais disseminado esse conhecimento dentro dos espaços, enfim, acho que mais possível de as pessoas conhecerem essa situação, saber o que é e conseguir conversar sobre isso. (Entrevista 1, mulher, branca, 41 anos, ensino superior completo) 
Uma cidade de Porto Rico, com alto índice de pobreza e desemprego, implementou uma estratégia para reduzir a violência por condiçáo socioeconômica entre os jovens. Comprovaram que os valores culturais e normas sociais influenciaram as intervençôes implementadas. As estratégias adotadas em relação ao problema de violência foram o diálogo aberto na comunidade e a criação de um grupo de discussão (MIRABAL et al., 2008).

Outro aspecto que emergiu das entrevistas é a importância de dialogar sobre os padróes culturais brasileiros que definem e mantêm estereótipos, bem como o papel de cada indivíduo na sociedade. Foi trazido que não importam a cor da pele, o sexo biologicamente definido, a idade ou outros fatores para determinar o status social do indivíduo.

Para isso tem que ter um permanente debate, um debate elevado... Qual o lugar do negro? Mulher? Homossexual? Então o homossexual o lugar dele é promiscuidade. Que história é essa de ser advogado e fazer uma audiência? Que história é essa de homossexual ser juiz? E de uma mulher bonita ser gay e ter outra mulher? Não combina, porque nos passaram esses padrốes... quando foge de um padrão a gente estranha... E quando não há um debate [...] a gente não percebe tanto e se acomoda. (Entrevista 2, homem, negro, 32 anos, ensino superior completo)

Corroborando essa proposta de enfrentamento, foi relatada a redução do estigma relacionado ao HIV através da formação de grupo de pessoas que proporcionaram educação comunitária. Tal redução foi obtida utilizando-se campanhas de mobilização dirigidas às suas comunidades (MBURU et al., 2013) ou discussôes coletivas entre profissionais de saúde e população Lésbicas, Gays, Bissexuais, Travestis e Transexuais (LGBT) (MOSCHETA; SOUZA; SANTOS, 2016). Esses métodos propiciaram práticas de trabalho mais inclusivas e sensíveis (MBURU et al., 2013; MOSCHETA; SOUZA; SANTOS, 2016).

\section{Educação informal: o ambiente familiar, a alteridade e o empoderamento}

Os participantes desta pesquisa enfatizam a importância de que a forma como a criança é educada pela família pode ser uma estratégia de enfrentamento da discriminação. Acreditam que na infância a criança está em processo de formação de caráter e valores. Entendem que o ambiente familiar é primordial para dialogar sobre as diferenças e igualdade. 
Teria que ter uma mudança desde o início. Primeiro é a educação dos pais. Quando começa a criança desde pequenininha a entender, explicar para a criança que é normal as pessoas serem diferentes. (Entrevista 12, mulher, branca, 36 anos, ensino superior completo)

No Brasil existe a compreensão da pluralidade cultural e do papel da família no trabalho da diversidade desde a infância, atentando-se para o fato de cada unidade familiar possuir um amplo aporte teórico para o estabelecimento do diálogo. Entende-se que isso se faz necessário para valorizar as diferenças e atitudes não discriminatórias (BRASIL, 1998).

Uma das formas descritas pelos entrevistados da pesquisa para trabalhar as diferenças é colocando-se no lugar do outro. Explicar de que maneira a pessoa discriminada se sente em determinadas situações e refletir se esta atitude discriminatória é justa e se faz bem ao outro. Formar uma consciência de não reproduzir o que é incorreto como expresso em:

Gostaria que fizesse tal coisa sobre ti nesse sentido? Não! Essa é minha educação básica. Minha família: não faça para os outros aquilo que não gostaria que fizessem para ti. (Entrevista 4, mulher, branca, 45 anos, ensino superior completo)

A alteridade é um termo que significa a capacidade de colocar-se no lugar do outro na relação interpessoal (grupos, família, amigos, lazer) e dialogar com esse outro (RAMOS, 2011). Esta relação entre o Eu e o Outro é influenciada pelas concepçôes culturais e ideológicas. Por vezes, alguém que represente uma diversidade cultural vai ser objeto de exclusão ou ameaça. Neste sentido, a alteridade permite a análise do mundo sob outro ponto de vista, em busca de uma sociedade mais igualitária. Por isso a importância de esta estratégia fazer parte do processo educativo e do desenvolvimento humano-social (RAMOS, 2011).

Outra estratégia desvelada nas entrevistas é o incentivo ao empoderamento da criança por parte dos pais. Explicar que as características físicas representam a identidade da raça/etnia e valorizar tais atributos. Tais características podem ser associadas a estereótipos negativos ou pejorativos. Incentivar o reconhecimento, a aceitação do próprio corpo e desmistificar os padróes de beleza atual são estratégias de enfrentamento.

Mas é muito forte a questão da família para a sociedade, quando vai aos locais, porque a criança, vejo pela filha da minha sobrinha, ela viu em algum lugar a questáo do cabelo crespo, que tem que alisar o cabelo. Porque ela vê que o bonito é o cabelo liso, quando se passam os produtos. E aí tu tens que dizer, teu cabelo é bonito, é crespo, tu és afrodescente, 
tem que dizer para a criança e ela tem que aprender a trabalhar essas coisas. (Entrevista 8, mulher, branca, 53 anos, ensino fundamental incompleto)

A teoria do empoderamento realça a capacidade dos indivíduos de fortalecer seu poder pessoal para responder a diversas formas de opressão. Quando as pessoas estão capacitadas, elas acreditam em sua habilidade de transformar as condiçôes sociais. Pais de crianças com deficiências que estavam empoderados agiram para criar ambientes mais inclusivos (NEELY-BARNES et al., 2010).

\section{Políticas públicas e leis}

Desvelando as entrevistas, emergiu a questão das políticas públicas como uma forma de enfrentamento, no sentido de promover a inclusão social. Essas estratégias de ações afirmativas têm o objetivo de tencionar mudanças de pensamento sobre as situaçóes. Relatam o papel educativo de políticas que versem sobre religiosidade, orientação sexual, posição da mulher em cargos públicos, por meio de cotas, campanhas ou outras formas. Também a relevância de adaptaçôes de algumas diretivas do governo, como a ampliação do público-alvo para campanhas de doação de sangue.

As organizaçôes teriam que promover isso, coisa que não fazem. Até políticas para conversar sobre isso. Porque têm as políticas afirmativas, até para mulher. Agora nas eleições até os partidos são obrigados por lei para ter cotas para as mulheres. Teve partido que até foi multado. (Entrevista 2, homem, negro, 32 anos, ensino superior completo).

[...] a questáo da doação de sangue, dado todos os exames que se tem hoje em dia, tu fazer uma barreira só porque a pessoa é homossexual, não faz mais sentido. (Entrevista 9 , homem, branco, 30 anos, ensino superior completo).

Outra forma de enfrentamento é o caráter punitivo das políticas públicas por meio da legislação. Acredita-se que para haver mudança de atitudes é também necessário agir de forma coercitiva, quando as consequências das atitudes se tornam onerosas, percebe-se a tendência de refletir sobre os hábitos. Entretanto, isso não implica necessariamente redução do preconceito.

É necessária uma lei que diga que racismo é crime [...] Elas não discriminam não porque elas deixaram de ser racistas, mas porque elas não querem sofrer um processo. (Entrevista 7, mulher, branca, 39 anos, ensino superior completo).

Mas além da estratégia ainda tem a coisa de criminalizar certas... tipo racismo. Eu acho que é interessante porque quando a pessoa sente no bolso e sabe que vai ser presa ou algo do tipo, criminalizada por isso, eu acho que dá uma refreada. (Entrevista 4, mulher, branca, 45 anos, ensino superior completo). 
A cultura local aparece como eixo norteador de políticas afirmativas. Ela pode definir se é necessária a legislação e a forma de implementação dessas para que haja transformaçôes positivas.

Acho que as coisas que partem de fora não têm muito resultado. Tipo, vai vir uma lei que
vai proibir. Não adianta, não adianta. É questáo de pensamento, de cultura. Não é porque
tem uma lei que náo vai deixar de tratar mal, que vai mudar o pensamento da pessoa.
[...]. Acho mais é cultural mesmo, de formaçáo do ser humano, de colocar na cabeça das
pessoas isso na escola ou até em programas. (Entrevista 12, mulher, branca, 36 anos,
ensino superior completo).

$\mathrm{Na}$ sociedade atual os padrões sociais são discutidos, contestados e o que se tentava coibir, ocultar, menosprezar vem galgando espaço na forma de legitimação. Muitas estratégias para o combate dos diversos atos discriminatórios vêm sendo instituídas no âmbito público e privado brasileiro. A Constituição Cidadã, que garantiu os direitos humanos, sociais e de trabalho à população brasileira. Outras leis que consideram crime o ato discriminatório, como a 7853/89 (contra pessoas portadoras de deficiência), 9029/95 (oriundas de raça, cor, estado civil, situação familiar, idade ou sexo) e 7716/89 (raça ou cor).

Existem iniciativas do governo federal voltadas à promoção da cidadania e combate à homofobia. Estas possuem a finalidade de capacitar as instituiçóes escolares, policiais, de saúde, judiciais a atuar de forma não homofóbica. A resolução 1652/2002 garante a realização da cirurgia de redesignação sexual e a alteração da identidade legal dos transexuais. Entretanto, observam-se obstáculos de combate à homofobia, já que os atos homofóbicos ocorrem no ambiente familiar, social e profissional na maioria das vezes. Nesse caso, nem sempre a solidariedade da família está presente para atenuar os efeitos da discriminação (GARCIA; SOUZA, 2010). Outra dificuldade é porque pesa uma condenação moral da sociedade, que trata, por vezes, a homossexualidade como doença. Muitos países religiosos, como a Arábia Saudita, o Irã e o Sudão, punem a homossexualidade com prisão ou pena de morte, por ser considerado crime. Em Uganda existe uma lei que impõe a prisão perpétua a homossexuais. São fatos que corroboram a influência do contexto cultural na formulação de estratégias de enfrentamento à discriminação.

\section{Mídias}

Os meios de comunicação, popularmente chamados de "mídia", que foram referenciados pelos adultos entrevistados incluem aparatos analógicos ou digitais para a 
comunicação das massas. O meio mais citado foi a televisão, que transmite informaçôes entre grupos heterogêneos de pessoas imersos em uma determinada cultura.

Nos relatos, as mídias foram citadas como uma forma importante de enfrentamento à discriminaçáo. Os sujeitos entendem o aspecto positivo de utilizar esses meios como base de discussão sobre os assuntos polêmicos. Seria um método de fortalecimento da ideia de igualdade entre os indivíduos, sobre os papéis que cada um ocupa na sociedade.

Acho que essa coisa da afirmação tem muito "global" agora estrelando. Eu acho que dá um reforço de autoestima na questáo racial, tem também a questão dos artistas gays ou trans aparecendo nas televisôes que pega a grande massa. (Entrevista 4, mulher, branca, 45 anos, ensino superior completo).

Há iniciativas diretas do uso da mídia para reduzir o estigma. Um exemplo é um documentário africano (KOMBO et al., 2017) cujo objetivo era iluminar, persuadir e educar o público-alvo sobre portadores de HIV. Outro exemplo é um documentário para diminuir a discriminação aos portadores de esquizofrenia (THONON et al., 2016). Em qualquer caso, a exposição à comunicação facilita a mudança de atitudes, uma vez que permite o acesso ao conhecimento. Um estudo mostrou que o esclarecimento sobre HIV e outras condiçôes de saúde permitiram maior aceitação dos portadores de HIV (BABALOLA; FATUSI; ANYANTI, 2009).

O papel midiático, sob outro ponto de vista, foi apontado como negativo em relação à discriminação. Isto ocorre uma vez que as mídias estabelecem padrôes culturais que suscitam injustiças, como nos padrôes de beleza feminina, enaltecendo a magreza, a cor da pele branca, o corpo longilíneo, ou na representação social inferior dos negros, deficientes ou homossexuais.

Uma educação que mostre para as pessoas que olha que um negro também é médico, negro também é escritor e não só uma educação, digamos assim, as mídias também porque hoje em dia a cultura é massivamente branca, a cultura negra é branquificada, enfim. (Entrevista 10, homem, negro, 31 anos, ensino superior completo).

A cultura influencia na mídia ao representar os padróes de beleza preestabelecidos na cultura ocidental. Tais padróes podem gerar malefícios na saúde dos indivíduos em busca de um corpo perfeito, através de cirurgias e procedimentos estéticos. Cabe ressaltar que, em determinadas circunstâncias, a mídia é influenciada pela cultura de minorias que detêm o poder local. Também contribui para atitudes vexatórias em relação aos obesos, ao associá-los ao fracasso e à tristeza. 
O papel das mulheres negras na mídia é representado de forma passiva e submissa. Muitas vezes, as atividades desenvolvidas por elas, como dança e esportes, valorizam somente seus atributos físicos. Em novelas brasileiras a representação do negro não é tão expressiva e, quando acontece, se dá na forma de escravo, malandro, empregada doméstica ou bandido (CICONELLO, 2001).

\section{Considerações finais}

A experiência aqui apresentada, com adultos servidores técnico-administrativos de uma universidade pública, possui relevância científica por sua temática. Uma vez que a discriminação é um fenômeno injusto, que permeia diversos espaços e contextos da sociedade. Os atos discriminatórios podem ocasionar sofrimento psicológico, adoção de comportamentos negativos (COELHO; BASTOS; CELESTE, 2015), como o consumo de álcool e tabaco, estresse, ansiedade, além das alteraçôes nos sistemas fisiológicos do organismo.

O presente trabalho apresenta ineditismo, uma vez que desvela um modelo de compreensão das estratégias para enfrentamento à discriminação entre servidores de uma instituição pública. O contexto cultural do indivíduo apresenta um papel central e interliga-se com as demais estratégias. As estratégias de enfrentamento e redução de preconceitos e discriminação são oriundas das experiências vividas ou presenciadas ao longo da vida dos entrevistados. Observou-se haver indícios de interseccionalidade (HIRATA, 2014) - i.e., ser mulher, ser negro(a), ter baixo nível educacional (entrevistas 3, 8, 11, 16). Entretanto, essa confluência de características, aumentando as chances de discriminação, não emergiu nas narrativas dos entrevistados, que apontaram apenas uma "causa principal" para a discriminação. Essa "invisibilidade" da interseccionalidade merece atenção, visto que múltiplas desvantagens sociais podem não só aumentar as chances de discriminação, mas gerar situaçóes particulares (BASTOS; HARNOIS; PARADIES, 2018). Importante destacar que o presente estudo não tinha o objetivo de explorar experiências de discriminação numa abordagem interseccional, e a ausência de tais relatos náo deveria ser interpretada como se refutasse tal abordagem. Futuros estudos devem aprofundar tais questôes. Entretanto, a ausência de percepçóes de discriminação motivada por múltiplas causas, neste estudo, pode explicar o porquê de os entrevistados náo relatarem estratégias específicas para combater tal discriminação de causas múltiplas. 
O modelo de enfrentamento à discriminação relatado neste estudo indica que as estratégias podem ser efetivas, quando formuladas de acordo com a cultura local. No presente momento, é escassa a reflexão científica sobre o efeito das estratégias de enfrentamento existentes na redução da discriminação. Em busca de uma sociedade mais igualitária e inclusiva, sugere-se o desenvolvimento de estudos futuros que avaliem as estratégias implementadas no Brasil e seus efeitos na diminuição da discriminação. As contribuições do presente estudo são a implementação das estratégias de enfrentamento à discriminação por instituições públicas e privadas e demais espaços da sociedade.

A pesquisa assume como limitação a opção pela técnica de amostragem por bola de neve, a qual prevê uma indicação do próximo participante a ser entrevistado. O número expressivo de servidores técnico-administrativo que ingressaram recentemente na universidade, bem como a diversidade do local em que atuam, pode ter fragilizado o potencial da "rede de indicaçôes" para as entrevistas. Alia-se a esse fato a natureza complexa do próprio tema de pesquisa, o qual pode trazer lembranças desagradáveis que causem sofrimento e constrangimento às pessoas que passaram por experiências discriminatórias. São pessoas que muitas vezes não se permitem falar sobre o assunto no seu local de trabalho, com seus colegas, inviabilizando ao pesquisador o reconhecimento delas como possíveis participantes de pesquisa. Nesses casos, a repetição das entrevistas para se conseguir maior aproximação entre pesquisador e entrevistado, permitindo relatos com maior aprofundamento das experiências discriminatórias vivenciadas, pode ser uma estratégia a ser considerada em futuras pesquisas. As conclusóes desta pesquisa não podem ser generalizadas para todos os adultos do município de Porto Alegre, mas, ainda assim, é possível fazer recomendaçôes referentes a estratégias para o enfrentamento da discriminação. ${ }^{1}$

\section{Referências}

ASSARI, S. et al. Racial discrimination during adolescence predicts mental health deterioration in adulthood: gender differences among blacks. Frontiers in Public Health, v. 5, p. 1-10, 2017.

BABALOLA, S.; FATUSI, A.; ANYANTI, J. Media saturation, communication exposure and HIV stigma in Nigeria. Social Science and Medicine, v. 68, n. 8, p. 1513-1520, 2009.

BARDIN, L. Análise de conteúdo. Lisboa: Ediçóes 70, 1977. 225p. 
BASÁNEZZ, T. et al. Perceived discrimination as a risk factor for depressive symptoms and substance use among Hispanic adolescents in Los Angeles. Ethnicity \& Health, v. 18, n. 3, p. 244-261, 2013.

BASTOS, J. L.; FAERSTEIN, E. Discriminação e saúde: perspectivas e métodos. Rio de Janeiro: Fiocruz, 2012.

BASTOS, J. L.; HARNOIS, C. E.; PARADIES, Y. C. Health care barriers, racism, and intersectionality in Australia. Social Science and Medicine, v. 199, p. 209-218, 2018.

BASTOS, J. L. et al. Experiences of discrimination among university students in the city of Rio de Janeiro. Revista de Saúde Pública, v. 44, n. 1, p. 28-38, 2010.

BIGLAN, A.; VAN RYZIN, M. J.; HAWKINS, J. D. Evolving a more nurturing society to prevent adverse childhood experiences. Academic Pediatrics, v. 17, n. 7, p. S150-S157, 2017.

BORGES, Z. N.; MEYER, D. E. Limites e possibilidades de uma ação educativa na redução da vulnerabilidade à violência e à homofobia. Ensaio: Avaliação e Políticas Públicas em Educação, v. 16, n. 58, p. 59-76, 2008.

BRASIL. Ministério da Educação e do Desporto. Secretaria de Educação Fundamental. Referencial curricular nacional para a educação infantil. Brasília: MED, 1998.

. Ministério dos Direitos Humanos. Secretaria Nacional de Políticas para Mulheres. Disponível em: <https://www.mdh.gov.br/navegue-por-temas/politicas-para-mulheresa>. Acesso em: 5 fev. 2019.

CAMPBELL, J. L. Ideas, politics, and public policy. Annual Review of Sociology, v. 28, n. 1, p. 21-38, 2002.

CARTER, S. E. et al. Anxiety mediates perceived discrimination and health in AfricanAmerican women. American Journal of Health Behavior, v. 40, n. 6, p. 697-704, 2016.

CICONELLO, A. O desafio de eliminar o racismo no Brasil: a nova institucionalidade no combate à desigualdade racial. In: GREEN, D. (Org.). Da pobreza ao poder: como cidadáos ativos e estados efetivos podem mudar o mundo. 1ed. São Paulo: Cortez Editora/Oxfam Internacional, 2009. p. 625-648.

COELHO, I. Z.; BASTOS, J. L.; CELESTE, R. K. Moderators of the association between discrimination and alcohol consumption: findings from a representative sample of Brazilian university students. Trends in Psychiatry and Psychotherapy, v. 37, n. 2, p. 72-81, jan. 2015.

COSTA, R. D. A.; SANTOS, T. R. L. dos. Representaçóes sociais de professores: desafios para socialização da criança negra na educação infantil. Tópicos Educacionais, v. 20, n. 1, p. 57-78, 2014. DOVIDIO, J. F. et al. Prejudice, stereotyping, and discrimination: theoretical and empirical overview. In: DOVIDIO, J. F. et al. (Editors). The Sage handbook of prejudice, stereotyping, and discrimination. London: Sage, 2010. p. 3-28. 
GARCIA, A.; SOUZA, E. M. DE. Sexualidade e trabalho: estudo sobre a discriminação de homossexuais masculinos no setor bancário. Revista de Administração Pública, v. 44, n. 6, p. 1353-77, dez. 2010.

GOFFMAN, E. Estigma: notas sobre a manipulação da identidade deteriorada. 4a ed. Rio de Janeiro: LTC Livros técnicos e científicos, 1988. 160p.

GOODMAN, A. et al. The healthcare experiences of Aboriginal peoples living in Vancouver's inner city, Western Aboriginal Harm Reduction Society. Social Science \& Medicine, v. 178, p. 87-94, 2017.

HIRATA, H. Gênero, classe e raça Interseccionalidade e consubstancialidade das relaçóes sociais. Tempo Social, v. 26, n. 1, p. 61-73, jun. 2014.

KOMBO, B. et al. "Facing our fears": using facilitated film viewings to engage communities in HIV research involving MSM in Kenya. Cogent Medicine, v. 4, n. 4, 2017.

KRIEGER, N. A glossary for social epidemiology. J Epidemiol Community Health, v. 23, n. 1, p. 693-700, 2001.

KRIEGER, N. Discrimination and health inequities. International Journal of Health Services, v. 44, n. 4, p. 643-710, 2014.

LEWIS, T. T.; COGBURN, C. D.; WILliAMS, D. R. Self-reported experiences of discrimination and health: scientific advances, ongoing controversies, and emerging issues. Annual Review of Clinical Psychology, v. 11, n. 1, p. 407-440, 2015.

LOPES, R. E. et al. Juventude pobre, violência e cidadania. Saúde e Sociedade, v. 17, p. 63-76, 2008.

MAJOR, B.; QUINTON, W. J.; McCOY, S. K. Antecedents and consequences of attribuitions to discrimination: Theoretical ans empirical advances. Law and Social Inquiry, v. 34, p. 251330, 2006.

MBURU, G. et al. Resisting and challenging stigma in Uganda: the role of support groups of people living with HIV. Journal of the International AIDS Society, v. 16, p. 1-7, 2013.

MENESES, A.; GOMES, A. Fenomenologia, humanizacão e promoção da saúde: uma proposta de articulação. Saude e Sociedade, v. 17, n. 1, p. 143-152, 2008.

MIRABAL, B. et al. Developing partnerships to advance youth violence prevention in Puerto Rico. The role of an academic center of excellence. American Journal of Preventive Medicine, v. 34, n. 3, suppl., p. S56-S61, 2008.

MOEHLECKE, S. Ação afirmativa: história e debates no Brasil. Cadernos de Pesquisa, p. 197$217,2002$. 
MOSCHETA, M. S.; SOUZA, L. V; SANTOS, M. A. Health care provision in Brazil: A dialogue between health professionals and lesbian, gay, bisexual and transgender service users. Journal of Health Psychology, v. 21, n. 3, p. 369-378, 2016.

NARDI, H. C.; QUARTIERO, E. Educando para a diversidade: desafiando a moral sexual e construindo estratégias de combate à discriminação no cotidiano escolar. Sexualidad, Salud y Sociedad (Rio de Janeiro), n. 11, p. 59-87, 2012.

NEELY-BARNES, S. L. et al. "It's our job": Qualitative study of family responses to ableism. Intellectual and Developmental Disabilities, v. 4, n. 48, p. 245-258, 2010.

PARADIES, Y. A systematic review of empirical research on self-reported racism and health. International Journal of Epidemiology, v. 35, n. 4, p. 888-901, 2006.

PARK, I. J. K. et al. Does anger regulation mediate the discrimination-mental health link among Mexican-origin adolescents? A longitudinal mediation analysis using multilevel modeling. Developmental Psychology, v. 53, n. 2, p. 340-352, 2017.

RAMOS, N. Educar para a interculturalidade e cidadania: princípios e desafios. Educação e formação de adultos: politicas, práticas e investigação. Coimbra: Imprensa da Universidade de Coimbra, 2011. p. 189-200.

SILVA, G. M. D. DA. Açôes afirmativas no Brasil e na África do Sul. Tempo Social, v. 18, n. 2, p. 131-165, 2006.

TAQUETTE, S. R. Interseccionalidade de Gênero, classe e raça e vulnerabilidade de adolescentes negras às DST/aids. Saude e Sociedade, v. 19, n. supl. 2, p. 51-62, 2010.

THONON, B. et al. The effects of a documentary film about schizophrenia on cognitive, affective and behavioural aspects of stigmatisation. Journal of Behavior Therapy and Experimental Psychiatry, v. 50, p 196-200, 2016.

TURATO, E. R. Tratado da metodologia da pesquisa clínico-qualitativa: construção teóricoepistemológica, discussão comparada e aplicação as áreas da saúde e humanas. 5a. ed. Petrópolis: Editora Vozes, 2011.

UNESCO. World Social Science Report 2016. Challenging Inequalities: Pathways to a Just World. Paris: UNESCO Publishing, 2016.

WALLACE, S.; NAZROO, J.; BÉCARES, L. Cumulative effect of racial discrimination on the mental health of ethnic minorities in the United Kingdom. American Journal of Public Health, v. 106, n. 7, p. 1294-1300, 2016.

WILLIAMS, D. R.; MOHAMMED, S. A. Discrimination and racial disparities in health: evidence and needed research. Journal of Behavioral Medicine, v. 32, n. 1, p. 20-47, 2009. 


\section{Nota}

${ }^{1}$ T. S. Badalotti realizou coleta, análise e interpretação dos dados; redação da primeira versão e aprovação da versão final. R. F. C. Toassi foi responsável pela concepção do artigo; análise dos dados; revisão crítica e aprovação da versão final. R. K. Celeste (bolsista de produtividade PQ2-CNPq - no 310978/2016-5) participou da concepção do manuscrito, análise dos dados, revisão crítica e aprovação da versão final. 


\section{Abstract}

\section{Facing the discriminatory phenomenon in adult population}

Discrimination is a social phenomenon that causes damage and inequities in health. This paper aimed to explore the discrimination and its ways of confrontation by university servants. This is a qualitative analytical study, using semi-structured individual interviews, interpreted by phenomenology. The sample was intentional, defined by the snowball technique. Thematic content analysis proposed by Bardin was used, with the help of NVivo software to define analytical categories. The main results reveal a model of confronting / combating discrimination, in which the categories are interrelated. The culture category occupies a central role, linking the strategies of quotas, formal education, legislation and public policies, media and informal education. Quotas allow access to formal education, which reduces discrimination and increases opportunities among individuals. Laws and policies change behavior by both its educational and coercive roles. The media allows interaction and discussion about us who are critical of discrimination in society. Informal education creates viable environments for discussion and encourages less discriminatory living since childhood. This study brings new perspectives and alternative approaches to understand ways to confront discrimination, which is an unfair phenomenon that crosses multiple spaces and social contexts.

Keywords: social discrimination; prejudice; strategies; qualitative research; phenomenology. 


\section{ERRATA}

No artigo "O ENFRENTAMENTO AO FENÔMENO DISCRIMINATÓRIO EM UMA POPULAÇÃO DE ADULTOS”, com número de DOI: http://dx.doi. org/10.1590/S0103-73312019290415 publicado no periódico Physis: Revista de Saúde Coletiva, v. 29, n. 4, e290415, na página 1, erro de nome de autor:

ONDE SE LÊ:

Tatiana Strümer Badalotti

LEIA-SE:

Tatiana Stümer Badalotti 